\title{
Exploring health status and care practices among children of female workers in unorganized sector
}

$\pi$
0
$\frac{\pi}{4}$
$\frac{\pi}{5}$
0

\section{Bansari Liladhar Chawada, Anjali Modi, Shantilal Lalichand Kantharia, Sanjeev Rao', Jayesh Khengarbhai Kosambiya}

Department of Community Medicine, ${ }^{1}$ Paediatrics, Government Medical College, Surat, Gujarat, India

Address for the Correspondence:

Dr. Bansari Chawada, Department of Community Medicine, Government Medical College, Surat Majura Gate, Surat - 395 001, Gujarat, India. E-mail: bansarichawada@gmail.com

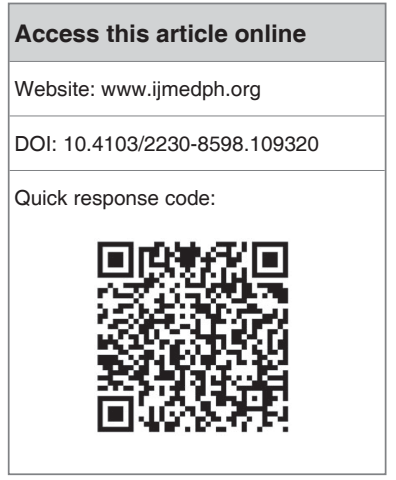

\begin{abstract}
Aims: To assess the health of children of construction workers with the help of anthropometric measurements and to explore their childcare practices. Settings and Design: Female construction workers and their children of age 12 to 36 months were taken as one study unit. The study had two components. One component deals with anthropometric measurements of the children while a qualitative descriptive exploratory component was used to explore mothers' perspectives and childcare practices. Methodology: Anthropometric measurements, background information, and living conditions were collected with the help of pre-tested and semi-structured questionnaire. In depth interview technique was used to explore child care practices. Total 14 mothers were interviewed to attain the saturation of responses. "Snow ball" technique was used to recruit children for anthropometric measurements and mothers for in-depth interview. Anthropometric analysis was done in WHO-ANTHRO software $v$ 3.0.1. Content analysis method was used to analyze emerging themes from the interviews. Results: Mean Z scores of weight for age, height for age, and MUAC was less than -1.5 . Among the children, $67.2 \%$ of children were underweight; $28.4 \%$ were wasted while $49.3 \%$ were stunted. All mothers believed breast milk to be good for baby for first few months, but only $11 \%$ of mothers could practice exclusive breast-feeding. Mothers' perspectives about childcare shows understanding about importance of breast-feeding, complementary feeding, balanced diet, and vaccination. However, mothers were not able to practice their knowledge in childcare; main reasons were fear of wage loss, unavailability of proper living facilities and influence of labor contractor. Conclusions: The study findings confirm the inequity of health among children of construction workers. Mainstreaming of the workers in unorganized sector and strict legislations ensuring good living conditions are recommended to combat child malnutrition among this group.
\end{abstract}

Key words: Child care practices, child malnutrition, construction workers, unorganized sector, WHO Anthro 2006 standards

\section{INTRODUCTION}

Provision of good health and health services for workers in unorganized sector is a daunting challenge for the health care providers and policy makers. The problem is more established among the children of workers in the construction industry. Children have special needs for growth and development, which are not met because of poor access to the basic health facilities and life amenities due to the temporary nature of stay of their parents at the construction sites..$^{[1,2]}$

A sizeable proportion (30.79\%) of married women in India migrates to urban areas to work as construction workers in unorganized sector along with their families as per estimates of National Sample Survey 2004-2005. ${ }^{[3,4]}$ Available literature shows the impact of working pattern, migration of parents, and living conditions upon nutritional and developmental parameters of children..$^{[2,5]}$

However, very limited literatures are available on growth and health situation of children belonging to the under-privileged section of community in India. Furthermore, no data is available to compare nutritional status of these children to WHO 2006 standards. Anthropometric standards by WHO 2006 are most reliable tools to assess child nutritional status everywhere in world regardless of ethnicity, socio-economic status, and type of feeding. ${ }^{[6]}$ Previous research also recommends studies 
to be conducted for exploring actual childcare practices to evolve health programs and recommend guidelines to ensure equity in child health and nutrition. ${ }^{[7]}$

With this background, the present study was conducted to explore the childcare practices and to estimate the health and nutrition status among children of construction workers. The study envisages the strategies for strengthening the child health status among the under-privileged groups.

\section{MATERIALS AND METHODS}

Surat is one of the fastest growing cities in India with a sizeable proportion of construction workers. The study was focused on the child health situation and care practices. WHO growth standards depict anthropometric measurements as useful and rapid tool to assess nutritional status of the children and thus help us to comment on their health. In-depth interviews helps to understand the perspectives, feelings, and actual practices of study participants.

\section{Study design and sample size}

Mixed method study design was adapted for the study with two components. One component deals with anthropometric measurements, background characteristics, history of illness, and living conditions of the children of 12 to 36 months of age whose mothers are working at construction site while for the other component, a qualitative descriptive exploratory design was used to explore mothers' perspectives and practices towards childcare practices.

\section{Study settings and duration}

The study was conducted in the settings of construction sites during May-July 2011 in New Civil Hospital Campus Surat, which was the place of temporary stay for the workers and their families.

\section{Study participants, recruitment}

The detailed information about the study was discussed with the employers, contractors, supervisors, and few key stakeholders; their approval for the study process was taken. Mothers working at the construction site and their children taken as one study unit were invited to take part in the study. There were 61 mothers with 67 children at the construction site. All 67 children were included after taking informed consent from parents to collect data for the first component of study.

"Snow ball" technique was used to recruit participants for in-depth interview where one participant gave reference for another potential participant. To avoid recall bias regarding early childcare practices, children up to only 36 months of age were included in the study.

Participants were contacted in their convenience time as per the schedule prepared in consultation with them for managing the operational aspect of the study. For all participants, around 15 minutes of duration was devoted for explaining study aims and objectives and taking informed consent before actual starting of data collection.

Diversity of the participants for qualitative component was taken cared by selecting of mothers having different parity and different age - sex of child. Adequate numbers of interviews were conducted to obtain saturation of responses. ${ }^{[8]}$

\section{Study methods}

Both study components of nutritional assessment and in-depth interview were conducted according to convenience of mother with the help of a brief questionnaire and topic guide.

In-depth interview techniques adopted from standard modules were used to conduct the study, as the study population was scattered. ${ }^{[9,10]}$ The investigators were trained for qualitative research and in-depth interview techniques with special emphasis on understanding of local language.

Interviews were done face to face by using in-depth interview technique with the help of topic guide. The topic guide included subjects like breast-feeding practices, complimentary feeding, and dietary practices. Other topics included were vaccination, services of Anganwadi, and health seeking behavior of mothers. Pilot testing was done once the interview guide was prepared. Total 21 questions were included in the guide.

All interviews were conducted by same researcher inside participants house when none other members were present to ensure privacy. No more than two interviews were conducted in one day. Transcribe of the verbatim were prepared on the same day of interview taking care of no loss of data. Data collection was continued until saturation of responses obtained. A total of 14 interviews were required to complete the study. Main themes of interview were perceived child health care, influential factors of each practice, barriers in childcare practices.

Analysis Content analysis method was used to analyze interviews. Transcribe were read repeatedly, and themes were classified according to emerging coding.

Anthropometric measurements like weight, height, mid upper arm circumference of the children were taken according to standard guidelines given in WHO modules of training course on growth assessment. Weight was measured by standardized weighting machine having accuracy of $0.1 \mathrm{~kg}$ allowing Tared weighing. ${ }^{[1]}$ Height was measured by standard measuring scale having accuracy of $1 \mathrm{~cm}$. For every child, three readings were taken, and their average was taken as weight and height of the child. Mid upper arm circumference (MUAC) was measured in middle of upper right arm. Current study utilizes the WHO growth standards as reference similar to other studies. ${ }^{[12]}$ Anthropometric measurements and health information were collected from all 67 children present on the construction site.

Analysis: Results of the first component were described as a cross-sectional study where one time observation and recording of weight, height, and MUAC were done for all 67 children. The data were entered and analyzed in WHO-ANTHRO software 3.0.1 to generates the $\mathrm{Z}$ scores and graphs, depicting distribution of various anthropometric parameters in relation WHO growth standards $2006 .^{[13]} \mathrm{Z}$ score is a score that indicates how far a measurement is from the median, also known as standard deviation (SD) score. The 
point labeled 0 is the median called as 'average,' and other z-score points are numbered positive $(1,2,3)$ or negative $(-1,-2,-3)$ depending on the distance from the median. They indicate how far an observation is from median (z-score 0$)$.

Underweight and severely underweight: $\mathrm{Z}$ score less than -2 and -3 , respectively.

Stunted and severely stunted: $Z$ score less than -2 and -3 , respectively.

Wasted and severely wasted: Z score less than -2 and -3 , respectively.

At the end of session, all mothers were counseled for affordable, available, safe, easy and healthy food preparations, importance of breast-feeding, and nutrition in children. They were given brief orientation towards expressed breast milk and nearest government health facility in co-ordination with faculties from Department of Pediatrics.

\section{RESULT}

A group of 61 working mothers, along with 67 children found at the construction site, was included in the study. The mean age of children was 23.13 months with a range of 12 to 36 months. Among 67 children, 34 were female and 33 were male. Mean age of female children was 24.10 months while mean age of male children was 22.12 months.

\section{Assessment of nutritional status}

The results of anthropometric measurements show the mean $\mathrm{Z}$ score of approximately all developmental parameters less than -1.5 as compared to standard mean score of zero in the WHO 2006 multicentric study [Table 1].

Figure 1 shows the distribution of the $\mathrm{Z}$ scores according to weight for age for both male and female children. Proportion of underweight $(Z$ score is less than -2 ) children was $67.2 \%$ while $11.9 \%$ of the children were found severely underweight ( $Z$ score is less than -3). Looking to sex-wise distribution, $66.7 \%$ of the male children and $67.6 \%$ female children were underweight while proportion of severely malnourish male were $21.2 \%$ as compared to $2.9 \%$ in females.

Proportion of stunted children according to the height for age was $49.3 \%$ while $4.5 \%$ of the children were severely stunted. Looking to sex-wise distribution, $45.5 \%$ of the male children and $45.9 \%$ female children were stunted while proportion of severely stunted male were $6.1 \%$ as compared to $2.9 \%$ in female. [Figure 2].

Proportion of wasted children according to weight for length/height was $28.4 \%$ while $4.5 \%$ of the children were severely wasted. Severely wasted males were $9.1 \%$ while none of the female child was found in severely wasted category. Similar graphs for MUAC and BMI were charted where $34.3 \%$ children had Z scores for MUAC less than -2 (undernourished) while $4.5 \%$ of the children had $Z$ scores less than -3 (severely undernourished). Sex-wise distribution shows $39.4 \%$ of the male children and $29.4 \%$ of the female children undernourished while proportion of severely undernourished male was $6.1 \%$ and female was $2.9 \%$ [Figure 3].

\section{Health and living condition}

Figure 4 depicts the history of illness episodes among children in last 3 months. Additional information collected about caretakers reveals that all children were taken cared by elderly siblings or children of other working mothers at the construction site. A common water tank was used for drinking, washing, and other purposes. Open air defecation and temporary houses with very primitive housing conditions were important findings.

\section{Results of in-depth interviews}

Time duration for each in-depth interview taken was 20 to 25 minutes, depending upon the participant responses. Number given at the end of the sentences is number given to participants of interviews. All names in the statements are pseudo names. The results of interviews were encoded according to themes of beliefs/information, influencing factors, and barriers.

\section{Breast-feeding practices}

Most mothers believed that 'breast milk is good for newly-born baby' (6) (7) (10) (14) and essential for the child for 'initial few months of life,' but only 11\% could practice exclusive breast-feeding for 6 months. According to women, doctors, health workers, family members were promoters of breast-feeding.

\section{Complementary feeding}

While exploring issues to bring children with them to the construction site, most of the working females avoided to bring small kids of age less than 6 months with them because of the lack of leave in between work to feed or care for child. As one woman said, "I need to come far for this work, and I used to leave him at home with my mother-in-law. Nobody is here (at the construction site) to look after children. Small kids need someone to look after them. She handled all about feeding of Rajesh... She used to give cow milk when he was too small to eat any food. (3) How can I bring my boy to work? After all, we are blessed by God with bim after two girls. ${ }^{(4)}$

\begin{tabular}{|c|c|c|}
\hline Weight-for-age & Mean Z score & $95 \% \mathrm{CL}$ \\
\hline Combined & -1.76 & -4.58 to -1.06 \\
\hline Male & -1.72 & -4.98 to 1.54 \\
\hline Female & -1.79 & -4.17 to 0.59 \\
\hline \multicolumn{3}{|c|}{ Length/height-for-age } \\
\hline Combined & -1.70 & -4.34 to 0.94 \\
\hline Male & -1.54 & -4.84 to 1.76 \\
\hline Female & -1.86 & -3.60 to -0.12 \\
\hline \multicolumn{3}{|c|}{ Weight-for-length/height } \\
\hline Combined & -1.22 & -3.96 to 1.52 \\
\hline Male & -1.33 & -4.29 to 1.63 \\
\hline Female & -1.11 & -3.61 to 1.39 \\
\hline \multicolumn{3}{|l|}{ MUAC for age } \\
\hline Combined & -1.50 & -3.44 to 0.44 \\
\hline Male & -1.65 & -3.61 to 0.31 \\
\hline Female & -1.36 & -2.31 to -0.41 \\
\hline \multicolumn{3}{|l|}{ BMI for age } \\
\hline Combined & -1.00 & -3.70 to 1.70 \\
\hline Male & -1.12 & -4.00 to 1.76 \\
\hline Female & -0.88 & -3.40 to 1.64 \\
\hline
\end{tabular}




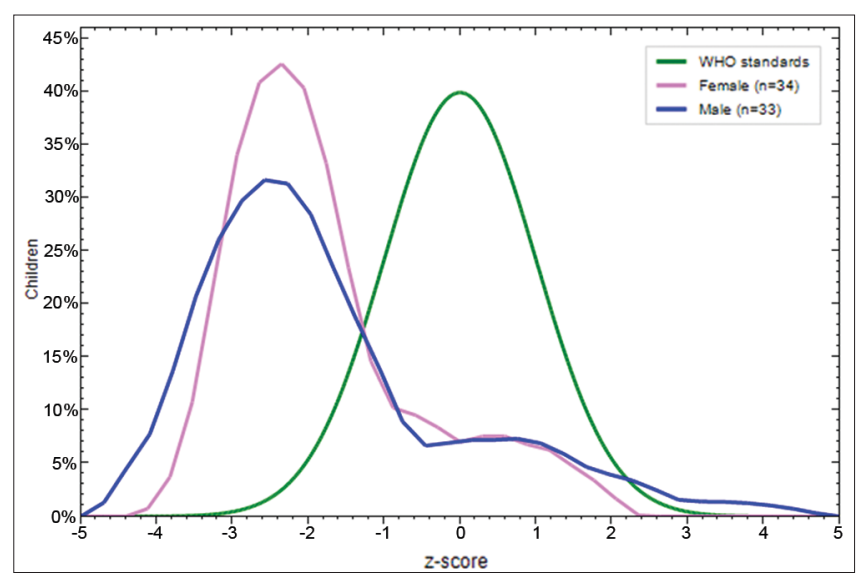

Figure 1: Distribution of $Z$ score according to weight-for-age

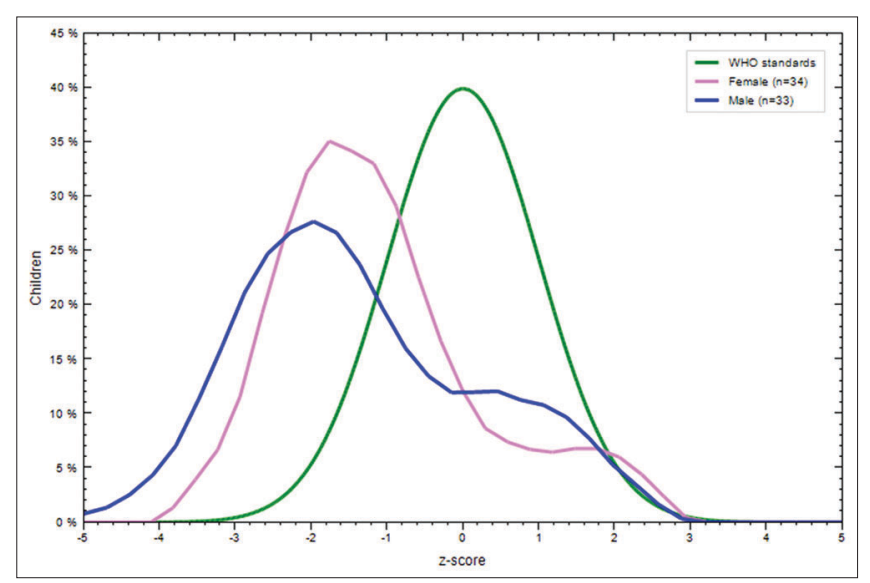

Figure 3: Distribution of $Z$ score according to weight-for-length/height

Nearly all mothers believe that the contractor can influence feeding practices to the extent that they start giving complimentary food at an earlier stage. One woman commented, "I start to feed rice to her as it cuts my wages if I took too many breaks. (7)"

This finding is in line with the finding of early starting of weaning (at 3 , 4 , or 5 months) among nearly $52.24 \%$ of the children.

On the other hand, $26.87 \%$ of the children had started weaning late (beyond 6 months). While exploring reasons for late weaning, mothers responded "to have no time to make semi-solid diet for the child." Some mothers believe that 'cow milk is a good substitute' of complementary food for child.

\section{Diet practices}

All women knew about the importance of balanced diet, but at the construction site, they had vegetarian diet consisting of Jowar or Wheat chapatti and locally available vegetables. Women quoted, "Dal-bhat (rice with pulses) is necessary for children as well for us. ${ }^{(2)}$ We all should take milk and Rice-Dal, but how I can make all here ${ }^{(14)}$ ? We took Rice-Dal, Salad, and milke. at village, but here I can prepare only Sabzi and Rotla (Traditional chapati) (14)."

\section{Vaccination}

Though almost all mothers knew about vaccination, $40 \%$ mothers were not aware about immunization status of their children. Reasons given were, "Dharm used to stay home, how can I know whether vaccine given or not. ${ }^{(8)}$

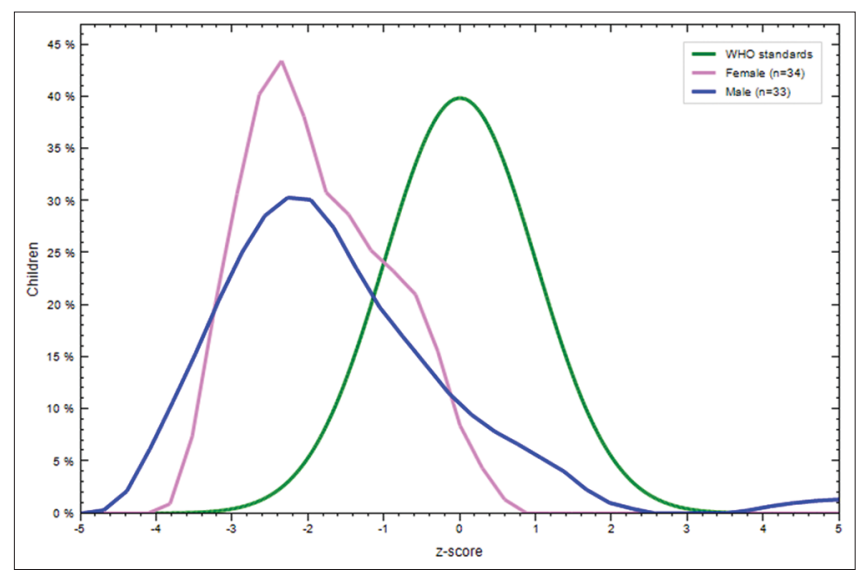

Figure 2: Distribution of $Z$ score according to length/height-for-age

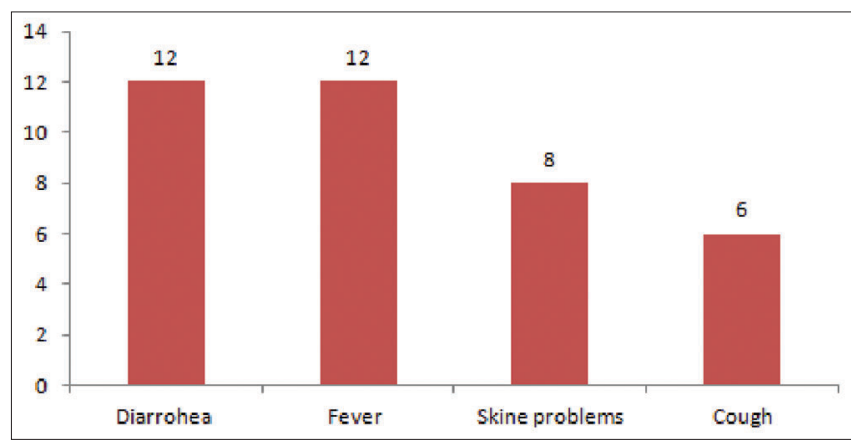

Figure 4: Number of episodes of communicable diseases during previous 3 months

I do not know about it. My grandmother took Ramesh for all tika (Vaccination)... I do not stay home. ${ }^{(13)}$ Sister (Anganwadi worker) calls for Rasi (vaccination), but I don't stay home most of the time, but she gave injection once, when I was there. ${ }^{(9) "}$ Immunization was completed by $17.91 \%$ of the children as per verbal communication with mothers. One mother informed, "We are here since one year and, therefore, vaccine is yet pending for Mansi (15 months old child.) (10)

\section{Services of Anganwadi}

All mothers were aware about Anganwadi centers at their residential village and the services provided, but they lacked information about similar services in city. Women told, "My home is just besides Anganwadi. Children of my village go there. They play and get meal there. (1) As we have to come for work, how we should send her in Aanganwadi? No Anganwadi is here (at the construction site). We send her Anganwadi whenever we go to village. ${ }^{(12)}$ I know Sushila bahen (Anganwadi worker) in village. We don't know any Anganwadi bahen bere. (1)

\section{Health-seeking behavior}

When women were asked about health-seeking behavior while at construction site: Most of the mother believes that they will bring the child to doctor only if "child is complaining or some visible illness is there." Mothers "took drugs for their children from" nearest chemist shop for any health complains or "visited nearby hospitals as advised by the mukadam" (contractor or person who appoints workers)." For all mothers, source of any information about health care services were their husbands. They also stated, "When we wish to go to hospital while at work, we need to take permission from contractor. ${ }^{(10)}$ ", 


\section{DISCUSSION}

The present study focused on the under-privileged group of female construction workers' children's nutritional assessment and care practices. This study utilized the WHO ANTHRO software to analyze the anthropometric measurements of children less than 3 years of age. Findings from current study show $61.7 \%$ of the children underweight, $28.4 \%$ wasted, and $49.3 \%$ stunted, which is far greater than the findings of National Family Health Survey III. ${ }^{[4]}$

More male children were found severely underweight $(21.9 \%)$ compared to female children $(2.9 \%)$, which is contrary to the observation, where no gender differentials were observed in the prevalence of under-nutrition. ${ }^{[14]}$ Mothers have quoted that they prefer to leave male children with caretakers at their permanent home in village for better care. This may be one important factor determining poorer health of male child as shown by findings of our study.

Exploration of mothers' perspectives about child care show understanding about importance of breast-feeding, complementary feeding, balanced diet, and vaccination. Though the breast-feeding was considered best practice by mothers, only $11 \%$ children could receive its benefit as compared to NFHS-III and study by Amrit et al. who show higher prevalence of exclusive breast-feeding among Indian population. ${ }^{[4,15]}$ Proportion of fully vaccinated children was merely $18.5 \%$. Although these workers are so close to the tertiary level health care center where regular immunization sessions are held and full treatment options are provided, the health status of these children is not satisfactory.

Timely introduction of complementary feeding were practiced only among $20 \%$ of mothers, which is again in sharp contrast to NFHS III findings. ${ }^{[4]}$ The current study findings of too early, too late introduction of complementary feeds, and poor young child feeding practices are important influencing factors for high prevalence of undernourishment among these children. ${ }^{[16]}$

Presence of illnesses like diarrhea, fever, respiratory infections suggest poor living condition for children. Trivedi et el. also found higher skin morbidities among construction workers. ${ }^{[17]}$ There was no provision for leave with wages to any workers. The same findings are observed by Parveen et el. ${ }^{[1]}$ In view of the services available almost next door, the health-seeking behavior of these women is surprising.

Fear of wage loss, influence of contractor in health-seeking behavior, and poor housing conditions are the major barriers in health-seeking practices. The same factors are observed in other studies. ${ }^{[18]}$ Workers were also not able to avail the benefit of Anganwadi services though they knew about existing health programs.

Summarizing the findings of current study, the workers were not able to practice their knowledge in relation to child care. Under-utilization of the existing government health schemes and compromised health status of children found in the study is an eye opener for health care providers and policymakers. There is an urgent need of introducing targeted interventions for under-privileged children in existing health care programs like provision of ready to eat supplements in monthly packages, serial weighing, vaccination, and medical checkups.
It is recommended to sensitize mothers by finding feasible solutions to their problems as expressed breast milk or easy and fast recipe of healthy food. Sensitization of local health workers to look after this migratory population along with local residential children of the community can also play a significant role. Alternatively, the employers can be bound to provide necessary amenities for healthy living. Implementation of mobile crèches, day care centers, and liveable conditions must be priority for this under-privileged group.

\section{CONCLUSION}

The study findings confirm the inequity of health among children of construction workers. The perspectives of mothers show their awareness about breast-feeding, complementary feeding, balanced diet, and immunization. Mothers were unable to practice their knowledge; main reasons were not able to care for child during long working hours, unavailability of proper cooking and living facilities, and dependence on labor contractor for utilization of available health schemes.

Interventions aimed at mainstreaming the children and their mothers working in unorganized sectors, in the existing health programs for women and child development, are strategies to combat child malnutrition in India. Enforcement of strict legislations ensuring good living conditions and access to health care and health benefits are required to ensure health equity among children and women.

\section{REFERENCES}

1. Nuzhat $P$, Patil NH. Women in informal sector: A case study of construction industry. Int Res J 2010;1:83-6.

2. Yu D, Liu A, Yu W, Zhang B, Zhang J, Jia F, et al. Status of malnutrition and its influencing factors in children under 5 years of age in poor areas of China in 2009. Wei Sheng Yan Jiu 2011;40:714-8.

3. National Sample Survey 2004-05. Building and other construction workers [Internet]. Available from: http://labour.nic.in/dglw/SChemes/ BuildingConstructionWorkers.html [Last cited on 2012 Jun 28].

4. Indian Institute of Population science. National Family Health Survey-III [Internet]. Mumbai 2006. p. 29. Available from: http://www. nihfw.org/ [Last accessed on 2012 Sep 1].

5. Ayaya SO, Esamai FO, Rotich J, Olwambula AR. Socio-economic factors predisposing under five-year-old children to severe protein energy malnutrition at the Moi Teaching and Referral Hospital, Eldoret, Kenya. East Afr Med J 2004;81:415-21.

6. de Onis M, Garza C, Onyango AW, Rolland-Cachera MF. le Comité de nutrition de la Société française de pédiatrie. WHO growth standards for infants and young children. Arch Pediatr 2009;16:47-53.

7. Kulwa KB, Kinabo JL, Modest B. Constraints on good child-care practices and nutritional status in urban Dar-es-Salaam, Tanzania. Food Nutr Bull 2006;27:236-44.

8. Guest G, Bunce A, Johnson L. How Many Interviews are Enough? An Experiment with Data Saturation and Variability. Vol. 18. Field Methods. United States: SAGE Publications; 2006. p. 59-82.

9. Mack N, Woodsong C, MacQueen KM, Guest G, Namey E. Qualitative Research Methods: A Data Collector's Guide [Internet]. USAID 2005. Available from: http://www.fhi.org/en/RH/Pubs/booksReports/QRM_ datacoll.htm [Last accessed on 2012 Sep 1].

10. Longsfield K. In-depth Interviews [Internet] 2004:1-92. Available from: http://www.aidsmark.org/ipc_en/pdf/manual/14_ Research-Toolkit-Ch6-In-Depth-Interviews.pdf [Last accessed on 2012 Sep 1].

11. World Health Organization. Training Course on Child Growth Assessment. Geneva; WHO; 2008.

12. Deshmukh PR, Dongre AR, Gupta SS, Garg BS. Newly developed WHO growth standards: Implications for demographic surveys and child health 
programs. Indian J Pediatr 2007;74:987-90

13. World Health Organization. WHO Anthro (version 3.2.2) [Internet]. Available from: http://www.who.int/childgrowth/software/en/ [Last cited on 2012 Jun 10].

14. Brahmam GN. National Nutrition Monitoring Bureau in India: An overview. Indian J Comm Med 2007;32:7-8.

15. Abrol A, Kalia M, Gupta B, Sekhon A. Maternal Health Indicator among Migrant Women Construction Workers. Indian J Community Med 2008;33:276-7.

16. Saloojee H, De Maayer T, Garenne ML, Kahn K. What's new? Investigating risk factors for severe childhood malnutrition in a high HIV prevalence South African setting. Scand J Public Health
Suppl 2007;69:96-106.

17. Trivedi A, Patel Y, Pandit N, Bhavsar B. Prevalence of Skin morbidity among construction site workers working at. Healthline 2011;2:31-3.

18. Kulkarni GK. Construction industry: More needs to be done. Indian J Occup Environ Med 2007;11:1-2.

How to cite this article: Chawada BL, Modi A, Kantharia SL, Rao S, Kosambiya JK. Exploring health status and care practices among children of female workers in unorganized sector. Int J Med Public Health 2013;3:38-43.

Source of Support: Nil, Conflict of Interest: None declared. 